\title{
Fabrication and Test Results for Rutherford-type Cables Made From BSCCO Strands*
}

\author{
R.M. Scanlan, D.R. Dietderich, H.C. Higley \\ Lawrence Berkeley National Laboratory, Berkeley CA, USA \\ K.R. Marken \\ Oxford Superconducting Technology, Carteret, NJ, USA \\ L.R. Motowidlo, R. Sokolowski \\ Intermagnetics General Corp., Waterbury, CT, USA \\ T. Hasegawa \\ Showa Electric Wire and Cable, Kawasaki, Japan
}

\begin{abstract}
Wires based on the Bi-2212 HTS superconductor are becoming available commercially, with current densities that are attractive for some applications. We report here on our success in using these $\mathrm{Bi}-2212$ wires to fabricate multistrand, kiloamp conductors that can be used to construct dipole and quadrupole magnets for particle accelerator applications. Multistrand cables have been made from several types of $\mathrm{Bi}$ 2212 wire supplied by two manufacturers. These cables were made with cores of various compositions and dimensions in order to optimize the fabrication process. In addition, cables have been made from aspected strands as well as round strands. Cable critical currents will be reported and compared for the various cable parameters investigated in this study.
\end{abstract}

\section{INTRODUCTION}

HTS superconductors based on the BSCCO compositions are now available in the form of wires that can be made in several hundred meter lengths, and with $\mathrm{J}_{\mathrm{c}}$ values that are becoming attractive for high field accelerator magnet applications [1]. However, several issues remain to be resolved before we can be confident that these materials will fulfill all the requirements for this application. The critical current of these wires is on the order of several hundred amps. In order to produce a high dipole field in a 10 meter long magnet, the operating current must be in the range of several kiloamps. This means that these wires must be assembled into a parallel current array. The most common method used for accelerator magnet applications has been the so-called Rutherford cable, where the wires are twisted and flattened to produce a flexible, transposed, high current conductor that can be bent around a small diameter to accommodate the ends of the magnet. This paper reports on the development of a Rutherford-type cable using multifilamentary $\mathrm{Bi}-2212$ wires with a $\mathrm{Ag} / \mathrm{Ag}$ alloy matrix, produced by Intermagnetics General Corp. (IGC) and Oxford Superconducting Technology (OST).

Manuscript received September 15, 1998

*This work is supported by the US Department of Energy under contact No: DE-AD03-76F00098

\section{Strand Fabrication AND Optimization}

OST strand was fabricated by conventional powder in tube and multifilament restack techniques. Starting 2212 powder with controlled characteristics was packed in a pure silver tube. The powder billet was drawn and hexed; then 121 hex wires were restacked in an alloy tube. The multicore billet was drawn to $0.8 \mathrm{~mm}$ final size, resulting in an average filament diameter of $40 \mu \mathrm{m}$. Strands were fabricated with two different metal/ceramic ratios, $2.3 / 1$ and $3 / 1$. The ratio was varied by changing the thickness of the tube used for the powder billet.

$\mathrm{J}_{\mathrm{c}}$ optimization was performed using a matrix of heat treatment trials. The parameters varied were, melt temperature, time and cooling rate from the melt. $I_{c}$ in the strands at $4.2 \mathrm{~K}$, self field, varied from a low of $40 \mathrm{~A}$ to a high of $179 \mathrm{~A}$. With optimum heat treatment parameters, $\mathrm{I}_{\mathrm{c}}$ values greater than $140 \mathrm{~A}$ were achieved reproducibly in these strands.

IGC multifilament BSCCO-2212 round wires were fabricated using the powder-in-tube approach. Wire designs included filament numbers from 84 to 310 with corresponding final average filament diameters ranging from 60 to $20 \mu \mathrm{m}$. The superconductor volume fraction ranged from 15 to $25 \%$. The conductor sheath included a Ag- $0.1 \% \mathrm{Al}$ matrix between the filaments with an outer jacket of pure silver. Processing was performed using standard LTS reduction schedules and final lengths were typically 200 to 300 meters. The wires were processed to a final diameter of $0.808 \mathrm{~mm}$. During the course of the program the critical current, $\mathrm{I}_{c}$, of these wires was significantly improved from about $55 \mathrm{~A}$ to over $200 \mathrm{~A}$ in self field at $4.2 \mathrm{~K}$ (see Table I). The $\mathrm{I}_{\mathrm{c}}$ enhancements were obtained as a result of introducing wire fabrication improvements and optimization of heat treatment parameters. The $\mathrm{I}_{\mathrm{c}}$ 's of one meter long helical wire samples were about 65 Amps at $12 \mathrm{~T}$ (at $1 \mu \mathrm{m} / \mathrm{cm}$ criteria), using the standard four point method, with voltage taps $25 \mathrm{~cm}$ apart. The corresponding $\mathrm{J}_{\mathrm{c}}$ in the superconductor is about $520 \mathrm{~A} / \mathrm{mm}^{2}$. 


\section{Cable Fabrication}

Previously, two types of Rutherford cables have been fabricated successfully from LTS wires - cored and coreless cables. For example, a core of stainless steel is used in order to provide a high resistance between the strands on each wide face of the cable and thus reduce the coupling losses in the cable [2],[3]. We decided to use a core in these HTS cables for two reasons: (1) to provide high interstrand resistance, and (2) to provide for a more gentle bending of the wire at the edge of the cable. Two thicknesses of cores were investigated $-0.390 \mathrm{~mm}$ and $1.092 \mathrm{~mm}$. Several candidate materials were tested for compatibility with the $\mathrm{Bi}-2212 / \mathrm{Ag}$ wires and we found that a $\mathrm{Ni}-\mathrm{Cr}$ alloy with a low $\mathrm{Fe}$-content was the best [4]. A series of cables were made from strand material provided both by IGC (Table I) and by OST (Table 2).

TABLE I.

IGC WIRES USED IN THIS STUDY

\begin{tabular}{ccccccc}
\hline $\begin{array}{c}\text { Sample } \\
\text { No. }\end{array}$ & $\begin{array}{c}\text { Fil. } \\
\text { No. }\end{array}$ & $\begin{array}{c}\text { Fil. } \\
\text { Diam., } \\
\text { (microns) }\end{array}$ & $\begin{array}{c}\text { S.C.vol. } \\
(\%)\end{array}$ & $\begin{array}{c}\text { Anneal } \\
\text { State* }\end{array}$ & $\begin{array}{c}\text { Ic(A) } \\
(4.2 \mathrm{~K}, 0 \mathrm{~T})\end{array}$ & $\begin{array}{c}\text { Remarks } \\
{ }_{*} * *\end{array}$ \\
\hline SN 240 & 294 & 23 & 15 & $\mathrm{CW}$ & 55 & N2 atm \\
SN 320 & 90 & 60 & 24 & $\mathrm{CW}$ & 75 & N2 atm \\
SN 251 & 84 & 60 & 20 & CW & & \\
SN 260 & 84 & 60 & 21 & CW & 10 & \\
SN 340 & 120 & 45 & 25 & CW & 25 & vac \\
SN 380 & 293 & 23 & 25 & CW & 200 & vac \\
SN 410 & 310 & 20 & 25 & CW/ann. & 225 & vac \\
SN 430 & 310 & 20 & 25 & CW/ann. & 135 & vac \\
SN 440 & 310 & 20 & 25 & CW/ann. & & \\
\hline
\end{tabular}

**N2 denotes billets packed under a nitrogen atmosphere; vacuum denotes billets evaluated before sealing.

TABLE II.

OST WIRES USED IN THIS STUDY

\begin{tabular}{|c|c|c|c|c|c|c|}
\hline $\begin{array}{l}\text { Sample } \\
\text { No. }\end{array}$ & $\begin{array}{l}\text { Fil. } \\
\text { No. }\end{array}$ & $\begin{array}{l}\text { Fil. Diam. } \\
\text { (microns) }\end{array}$ & $\begin{array}{c}\text { S.C. } \\
\text { vol. (\%) }\end{array}$ & $\begin{array}{l}\text { Anneal } \\
\text { State* }\end{array}$ & $\begin{array}{c}\text { Ic(A) } \\
(4.2 \mathrm{~K}, 0 \mathrm{~T})\end{array}$ & Remarks \\
\hline PM040997 & 121 & 40 & 30 & $\mathrm{CW}$ & $80-179$ & Improved \\
\hline PM041797 & 121 & 40 & 30 & CW/ann. & $40-149$ & heat treatmen \\
\hline PM082897 & 121 & 40 & 25 & $\mathrm{CW}$ & & \\
\hline
\end{tabular}

${ }^{*} \mathrm{CW}$ denotes wire drawn to final size without annealing; ann. refers to wire given a final or intermediate anneal at $350 \mathrm{C}$.

Cables were made with the two thicknesses of cores, and the cable parameters are listed in Table II. Several parameters were changed in comparison to those used in LTS cables. First, the strand tension was reduced from the $5 \mathrm{~kg}$ used for $\mathrm{NbTi}$ to about $1.5 \mathrm{~kg}$. Second, the degree of compaction was reduced from around $90 \%$ to $85 \%$. Finally, no attempt was made to twist the strands. After these changes were made, cables could be fabricated without excessive wire breaks with both the IGC and OST wires. However, occasional wire breaks occurred with both types of wires. The tendency for wire breaks increased as the Bi-2212 powder content was increased from around 15 to $25 \%$. Cables were made with both thin cores (18 strands) and thick cores (19 strands) and sent to IGC or OST for heat treatment and $I_{c}$ testing. Cross sections of the thin core and thick core cables made from OST wire are shown in Fig 1.

TABLE III.

CABLES MADE FROM IGC WIRES

\begin{tabular}{|c|c|c|c|c|}
\hline Cable \# & Strand I.D. & Strand \# & $\begin{array}{l}\text { Core Mat'l } \\
\text { Thick. (mm) }\end{array}$ & $\begin{array}{c}\mathrm{Ic}(\mathrm{A}) @ \mathrm{~T} \\
(4.2 \mathrm{~K})\end{array}$ \\
\hline 613 & SN 380 & 18 & $\begin{array}{c}\text { Nichrome } \\
0.390\end{array}$ & $\begin{array}{c}\text { 1080@0T } \\
650 @ 8 T\end{array}$ \\
\hline 614 & SN 380 & 19 & $\begin{array}{c}\text { Nichrome } \\
0.390\end{array}$ & $2100 @ 0 \mathrm{~T}$ \\
\hline $614 \mathrm{~A}$ & SN 380 & 19 & $\begin{array}{c}\text { Nichrome/ } \\
\text { MgO tape } \\
1.092\end{array}$ & $\begin{array}{l}3400 @ 0 \mathrm{~T} \\
1650 @ 4 \mathrm{~T}\end{array}$ \\
\hline 640 & $\mathrm{SN} 410$ & 19 & $\begin{array}{l}\text { Nichrome/ } \\
\text { MgO tape }\end{array}$ & \\
\hline 641 & SN 430 & 19 & $\begin{array}{l}\text { Nichrome/ } \\
\mathrm{MgO} \text { tape }\end{array}$ & \\
\hline
\end{tabular}

TABLE IV

CABLES MADE FROM OST WIRES

\begin{tabular}{cccccc}
\hline Cable \# & Strand I.D. & Strand \# & $\begin{array}{c}\text { Core Mat'l } \\
\text { Thick. }(\mathrm{mm})\end{array}$ & $\begin{array}{c}\text { Ic(A)@ T } \\
(4.2 \mathrm{~K})\end{array}$ & Remarks \\
607 & PM040997 & 19 & Nichrome 1.092 & 950 & \\
608 & PM040997 & 18 & 0.390 & 920 & \\
643 & PM041797 & 19 & Nichrome 1.092 & & Strand annealed \\
\hline
\end{tabular}

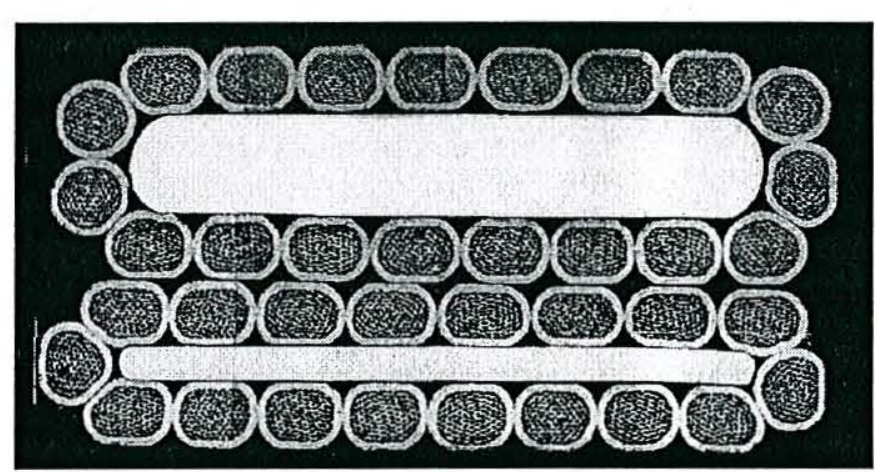

Fig. 1 Oxford HTS (Bi-2212) with Ni-Cr core; Top \#607; Bottom \#608

\section{Test Results}

In order to investigate the possibility of cabling degradation and/or core contamination, the following sequence of tests were performed. $I_{c}$ measurements were made on (1) uncabled wires, (2) wires removed from the cable, and (3) the cables with cores in place. Slightly different methods are used at IGC and OST for the heat treatment and cable testing. At OST, the cable is wrapped on a $100 \mathrm{~mm}$ diameter mandrel (1.25 turns, $400 \mathrm{~mm}$ long), heat treated, and transferred to the test mandrel which is $95 \mathrm{~mm}$ in diameter. The sample is soldered to the test mandrel with a voltage tap spacing of about $360 \mathrm{~mm}$. The test fixture is then placed in a solenoid with a background field of $5 \mathrm{~T}$ and with a testing current limit of $1000 \mathrm{~A}$. The $I_{c}$ is then measured and reported at a 1 microvolt $/ \mathrm{cm}$ criteria. The results for one series of OST cables are shown in Fig 2. In addition to the data for the full cable, data are also shown for the wires-before cabling and for wires removed from the cable and tested individually. 


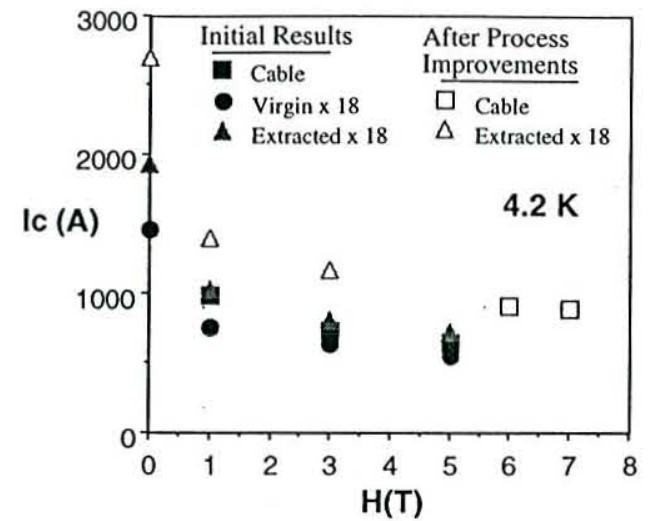

Fig. 2 Critical current vs. field for Cable 608 (OST wire)

The data points labeled "Initial Results" show that the $I_{c}$ results for both the full cable and the extracted strands are in close agreement. These results indicate that there is little degradation, either by the cabling operation or by contamination by the core, for this particular heat treatment and strand combination. Following the initial tests, the heat treatment was modified to improve the strand $\mathrm{J}_{\mathrm{c}}$. This produced a significant increase in the cable critical current, to $820 \mathrm{~A}\left(\mathrm{~J}_{\mathrm{c}}=345 \mathrm{~A} / \mathrm{mm}^{2}\right)$ at $7 \mathrm{~T}$. Data could not be taken below $6 \mathrm{~T}$ due to the $1000 \mathrm{~A}$ power supply limitation.

At IGC, the cables were heat treated on a 100

$\mathrm{mm}$ diameter mandrel and transferred to a $90 \mathrm{~mm}$ diameter mandrel for testing. A cable length of 2.27 meters was used, with $100 \mathrm{~mm}$ between the primary voltage taps. $\mathrm{I}_{\mathrm{c}}$ values are reported using a 1 microvolt/cm criteria. The cable $I_{c}$ vs. field for the initial tests are shown in Fig. 3, labeled 614.

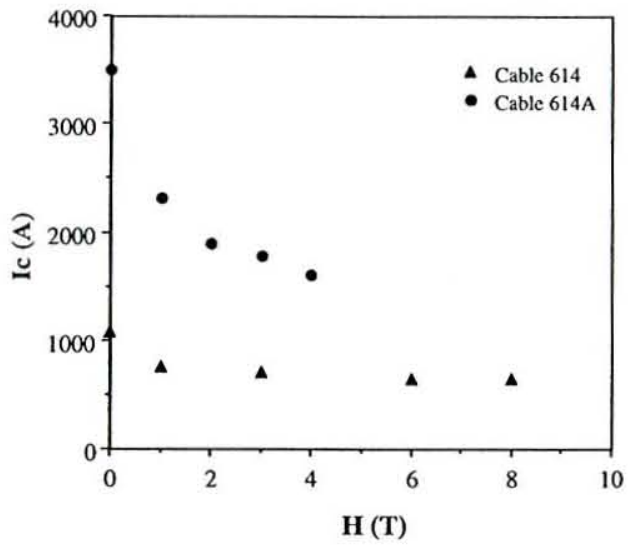

Fig. 3 Critical current vs. Field for cable 614 and $614 \mathrm{~A}$

In addition to the primary voltage taps over a $100 \mathrm{~mm}$ sample length, secondary voltage taps were placed on strands in the straight, flat sections of the cable and also at the edges of the cable. Although the sensitivity of the measurement is reduced compared to the total sample length measurements, the results show a systematic difference between the $I_{c}$ measured on the flats and the edges. The $\mathrm{I}_{\mathrm{c}}$ values $(4 \mathrm{~K}, 0 \mathrm{~T})$ of the straight section are $195 \mathrm{~A}$, whereas the values at the edges are $164 \mathrm{~A}$, e.g. similar to the values measured for the entire wire length of $166 \mathrm{~A}$. Although the IGC test results on $\mathrm{I}_{\mathrm{c}}$ measurements at the cable edges compared with the cable flat faces showed that some cabling degradation was present, in general the cable $\mathrm{I}_{\mathrm{c}}$ degradation appeared acceptable.

IGC and Showa made significant improvements in the cable $I_{c}$ during this program by changing the wire fabrication, cable core, and heat treatment parameters. The best $\mathrm{I}_{\mathrm{c}}$ value for the cables made from IGC wire, heat treated and tested at Showa, are labeled 614A. Several changes were made in the processing of this cable. In order to insure that contamination was not occurring in the low $\mathrm{Fe}$ content nichrome cores, Showa removed the core, wrapped the core with $\mathrm{MgO}$ insulation, and reassembled the cable. In addition, a modified heat treatment was employed, and the sample was tested as a $50 \mathrm{~mm}$ straight sample, with $10 \mathrm{~mm}$ voltage tap spacing, instead of a coil. The cable $I_{c}$ for this test represents the highest $I_{c}$ obtained to date in this study $\left(I_{c}=1650 \AA ; J_{c}=760\right.$ $\left.\mathrm{A} / \mathrm{mm}^{2}, 4 \mathrm{~T}\right)$.

Although cables of sufficient length for these tests could be made routinely, attempts to make cables in tens of meter lengths resulted in an unacceptable level of strand breakage. This problem was overcome by annealing the wire before cabling. A significant change in mechanical properties of the wires occurred as a result of this annealing step. The yield stress was reduced from approximately $210 \mathrm{Mpa}$ to $66 \mathrm{Mpa}$ and the elongation increased from about $2 \%$ to over $5 \%$. After annealing was introduced, no strand breakage has been observed in the fabrication of 5-10 m lengths of cables.

\section{Conclusions}

A number of challenges have been met and overcome during this program aimed at developing HTS cables for accelerator magnet applications. First, the wire $I_{c}$ values have been increased from the early wires, which had values in the range of $10-75 \mathrm{~A}$ to the present where greater than $200 \mathrm{~A}$ is the norm. Cable $I_{c}$ degradation and ac losses have both been minimized by use of a core [4]. Possible contamination of the $\mathrm{Bi}-2212$ wires by the core has been reduced by the use of low-Fe nichrome ribbons. It appears that contamination can be reduced further by coating these ribbons with $\mathrm{MgO}$. Most importantly, strand breakage has been eliminated by annealing the strands before cabling. The best cables in this series have an $\mathrm{I}_{\mathrm{c}}$ exceeding $1650 \mathrm{~A}$ at $4.2 \mathrm{~K}$ and $5.0 \mathrm{~T}$. When extrapolated to 30 strand cables and to $16 \mathrm{~T}$, these $\mathrm{Bi}-2212 \mathrm{~J}_{\mathrm{c}}$ values are comparable to the values being obtained at present 
for $\mathrm{Nb}_{3} \mathrm{Sn}$ cables. However, several significant challenges remain. First, the matrix: superconductor ratio should be reduced from the present 3:1 to a value sufficient for magnet protection, i.e. nearer to $1: 1$. In addition, the $I_{c}$ vs. strain characteristics must be measured and the strain limits established for the HTS cables.

\section{Future Plans}

The next phase of this program is the fabrication of $100 \mathrm{~m}$ lengths of cable. The effect of strain on the $I_{c}$ will be evaluated in measurements both parallel and perpendicular to the wide face of the cable. Small racetrack coils will be fabricated and tested in the background field produced by LTS racetrack coils [5]. The billet size used in strand fabrication will be increased in order to reduce the unit costs. React and wind racetrack coils will be made in order to evaluate the utility of this process for accelerator dipole magnets.

\section{ACKNOWLEDGMENTS}

We would like to acknowledge the assistance provided by Ted Collings and his group at Ohio State University in the choice of the core material. Also, we appreciate the help of Professor Eric Hellstrom in optimizing the power in tube processing, in particular the elimination of the nitrogen atmosphere as a source of porosity.

\section{REFERENCES}

1. L.R.Motowidlo and R.S.Sokolowski, "BSCCO(2212) Multifilament Wires for Magnet Applications at 4.2K", paper MHA-03, these proceedings.

2. M.D.Sumption et.al., ADV. In Cryo.Eng.(Materials) 44, in press.

3. E.W.Collings et.al., "Suppression and Control of Coupling Currents in Stabrite-coated Rutherford Cable with Cores of Various Materials and Thicknesses", IEEE Trans.in Applied Supercond.7 (1997), 962.

4. E.W.Collings, M.D.Sumption, R.M.Scanlan, and L.R.Motowidlo, "Low Eddy Current Loss in Rutherford Bi:2212 Accelerator Cables with Cores", paper LLB-01, these proceedings.

5. K.Chow et.al., "Fabrication and Test Results of a Prototype, $\mathrm{Nb}_{3} \mathrm{Sn}$ Superconducting Racetrack Magnet", paper LQA-01, these proceedings. 


\section{LEGAL NOTICE}

This report was prepared as an account of work sponsored by the United States Government. Neither the United States nor the Department of Energy, nor any of their employees, nor any of their contractors, subcontractors, or their employees, makes any warranty, express or implied, or assumes any legal liability or responsibility for the accuracy, completeness or usefulness of any information, apparatus, product or process disclosed, or represents that its use would not infringe privately owned rights. 